\title{
FORMAÇÃO INICIAL DE PROFESSORES EM UMA INSTITUIÇÃO DE EBPT: Desafios a Partir do Olhar dos Egressos
}

\author{
Danieli Melo Zarzicki ${ }^{1}$ \\ Neiva Maria Frizon Auler ${ }^{2}$
}

\begin{abstract}
RESUMO
Este artigo aborda a contribuição dos cursos de Licenciatura do Instituto Federal Farroupilha Campus Alegrete na formação docente e como se deu a inserção dos seus formandos no ambiente educacional. O estudo focou nos ingressantes dos cursos de Licenciatura em Ciências Biológicas, Química e Matemática, entre os anos de 2010 e 2014. A análise dos dados ocorreu por meio da Análise Textual Discursiva (ATD), mediante a realização de uma entrevista com egressos atuantes na docência. Como resultados verificou-se que, nesses cursos de Licenciatura, no período estudado, o Pibid, estágios curriculares e atividades de laboratório foram apontados como pontos positivos da formação. Por outro lado, as fragilidades destacadas foram a pouca regência em sala de aula, tardia oferta de Libras na matriz curricular e pouca importância para Educação Especial. Por conseguinte, os redimensionamentos necessários foram elencados a partir da discussão estabelecida a respeito da oferta da disciplina de Libras, bem como do acesso ao conteúdo da educação especial, juntamente com mais tempo para as práticas de estágio curricular obrigatório (ou optativo) e práticas de laboratório, as quais também foram consideradas fundamentais no processo formativo.
\end{abstract}

Palavras-chave: Formação de professores; cursos de Licenciatura; educação profissional e tecnológica; egressos.

\section{INITIAL TEACHER EDUCATION AT AN EBPT INSTITUTION: CHALLENGES FROM THE PERSPECTIVE OF GRADUATES}

\section{ABSTRACT}

This article discusses the contribution of undergraduate courses at the Federal Institute Farroupilha Campus Alegrete to teacher training and how their graduates were inserted in the educational environment. The study focused on newcomers to the Licentiate Degree Courses in Biological Sciences, Chemistry and Mathematics, between the years 2010 to 2014. The research had a qualitative focus by conducting an interview with alumni working in teaching. As a result, it was found that, in these degree courses, in the period studied, Pibid, curricular internships and laboratory activities were pointed out as positive points of training. On the other hand, the weaknesses highlighted were the little regency in the classroom, late offering of Libras in the curriculum and little importance for Special Education. Therefore, the necessary resizing were listed from the discussion established regarding the offer of Libras subjects, as well as access to the content of special education, along with more time for mandatory (or optional) curricular internship practices and practices of laboratory, which were also listed as fundamental in the training process.

Keywords: Teacher training; degree courses; professional and technological education. Graduates.

RECEBIDO EM: $15 / 8 / 2021$

ACEITO EM: 25/11/2021

Instituto Federal Farroupilha - Campus São Vicente do Sul. São Vicente do Sul/RS, Brasil.

2 Autora correspondente. Instituto Federal Farroupilha - Campus São Vicente do Sul. R. Vinte de Setembro, 2616. São Vicente do Sul/RS, Brasil. CEP 97420-000. http://lattes.cnpq.br/4721165773734294. http://orcid.org/0000-0002-6286-8265. n.auler@iffarroupilha.edu.br 


\section{INTRODUÇÃO}

No dia 29 de dezembro de 2008 foi sancionada a Lei no 11.892, criando os Institutos Federais de Educação, Ciência e Tecnologia (IFs), instituições estas pautadas pelo ensino voltado à Educação Profissional e Tecnológica. A partir de então surge também a obrigatoriedade dos IFs de destinarem o mínimo de $20 \%$ de suas vagas para a formação de professores em suas instituições, desenhando-se desta forma um novo cenário, antes permeado apenas pela habilidade no exercício nas áreas técnicas.

No Instituto Federal Farroupilha (IFFar), 8 dos 11 campi situados em diversos municípios do Estado do Rio Grande do Sul ofertam cursos de Licenciatura e, destes, o Campus Alegrete (local do presente estudo) é o que oferece o maior número de cursos: Ciências Biológicas, Química e Matemática. Essa oferta iniciou-se em 2010, com o curso de Licenciatura em Química e somou até o ano de 2018 um total de 5 (cinco) turmas de egressos deste curso (2010, 2011, 2012, 2013 e 2014) e um total de 4 (quatro) turmas de egressos (2011, 2012, 2013 e 2014) dos cursos de Licenciatura em Ciências Biológicas e Matemática, compondo um número significativo de alunos com formação docente concluída (49 de Ciências Biológicas, 41 de Química e 33 de Matemática).

Os Projetos Pedagógicos dos Cursos (PPCs) de Licenciatura ofertados no campus Alegrete fazem referência à carência de professores nas áreas de Ciências e Matemática, principalmente na Educação Básica, no município, contribuindo para que uma grande parcela de profissionais docentes já formados atue em regime de contrato temporário e fora da sua área de atuação específica para atender à demanda da rede pública e privada do município e região. Além disso, a extinção da oferta de cursos superiores nessas áreas pelas universidades privadas e comunitárias regionais resultaram em uma urgente necessidade de atender às demandas profissionais nas áreas anteriormente citadas.

Ao considerarmos as especificidades destas instituições (IFs) verificamos que sua singularidade, além da própria especialidade em trabalhar com a Educação Profissional e Tecnológica, apresenta-se na oferta de formação desde a Educação Básica até a Pós-Graduação, nas quais um mesmo docente pode atuar ao longo de sua carreira. Constata-se também que estas instituições continuam privilegiando as Licenciaturas para as disciplinas científicas, seguindo um modelo de currículo trabalhado no âmbito das universidades. Apesar de serem instituições prioritariamente de educação profissional, ainda não se assumem como tal.

O presente estudo objetivou contribuir para a melhoria na formação no âmbito das Licenciaturas (com foco na Educação Básica Profissional e Tecnológica - EBPT), por meio da identificação de atributos ou de possíveis fragilidades que envolvam o processo de atuação profissional dos egressos dos cursos de Licenciatura do Instituto Federal Farroupilha do Campus de Alegrete/RS (Licenciatura em Matemática, em Química e em Ciências Biológicas), proporcionando uma avaliação dessas formações tendo em vista a obrigatoriedade da oferta de cursos de Licenciatura nos Institutos Federais.

Cabe destacar que este artigo é um recorte de uma pesquisa mais ampla intitulada "Atuação profissional de egressos dos Cursos de Licenciatura IFFar Campus Alegrete", dissertação esta apresentada ao Programa de Pós-Graduação em Educação Profissional e Tecnológica - PROFEPT. 


\section{PERCURSO METODOLÓGICO DA PESQUISA}

A presente pesquisa teve enfoque qualitativo, mediante a aplicação de questionário e realização de entrevistas com os egressos que seguiram na carreira docente. Nesse sentido este tópico foi organizado em duas etapas, descritas a seguir:

A etapa 1 consistiu no encaminhamento de um questionário com perguntas abertas e fechadas, o qual objetivou identificar questões ligadas à formação docente e à quantidade de egressos dos cursos de Licenciatura do Campus Alegrete, do IF FarroupiIha, que efetivamente atuam na docência, resultando em um panorama geral acerca da formação e atuação profissional dos egressos. O referido questionário foi encaminhado para todos os licenciados egressos dos referidos cursos no período compreendido entre 2014 e 2018. A chamada de participação da pesquisa foi realizada via correio eletrônico, contato telefônico, chamadas nas redes sociais, contatos com as Coordenadorias de Graduação e professores dos cursos, entre outros.

$\mathrm{Na}$ etapa 2 foram realizadas entrevistas tendo como objetivo aprofundar elementos novos não detalhados no questionário inicial e aprofundar as questões referentes ao ensino, formação inicial (pontos fundamentais e aspectos passíveis de alteração) e continuada, Educação Profissional e Tecnológica e currículo integrado.

A natureza da entrevista foi semiestruturada e realizada somente com os egressos atuantes na docência - condição esta manifestada em resposta ao questionário. Desse modo, a entrevista foi formulada a partir de elementos considerados frágeis, inconclusivos ou relevantes no questionário, como o distanciamento com conteúdos relacionados à Educação Básica Profissional e Tecnológica (EBPT), à grande diversidade de formações em outras graduações em licenciaturas bem como em outras áreas de conhecimento, após a conclusão da Graduação. Além disso, a necessidade de aperfeiçoamento após a formação inicial ou mesmo de alguma mudança para outra área, elementos estes que foram substancialmente apontados pelos egressos.

Cada participante foi contatado individualmente e assinou o Termo de Consentimento Livre e Esclarecido para início da intervenção (entrevistas). Todos os colaboradores receberam o termo de confidencialidade respaldando o sigilo das informações, bem como o seu anonimato. Os participantes receberam uma codificação com a letra $E$, seguida de um algarismo conforme a sequência das entrevistas $(1,2,3,12)$. Os dados das entrevistas foram obtidos por meio de áudio gravado em aparelho digital (celular) e alocados em um banco de dados. Após a realização das entrevistas, todas foram transcritas, preservadas as formas e expressões utilizadas pelos participantes, com algumas alterações que possibilitam aos leitores uma experiência mais padronizada, retirando-se expressões de fala (hã, $\mathrm{mmm}$, etc.). O respaldo ético do CEP - IFFar se dá pelo Parecer CAAE no 99355018.0.0000.5574 de 2019.

Os dados obtidos nesse processo (entrevistas) foram submetidos à Análise Textual Discursiva (ATD), pois o seu uso mostra-se como um mecanismo importante nas metodologias de análise textual, principalmente em pesquisas de cunho qualitativo que se utilizam de uma multiplicidade detalhada de informações coletadas por meio de análise profunda dos discursos pelo pesquisador. 
De acordo com Moraes e Galiazzi (2011), a Análise Textual Discursiva pode ser compreendida como um processo auto-organizado de construção de compreensão em que novos entendimentos emergem de uma sequência recursiva de três componentes: a desconstrução dos textos do "corpus", a unitarização; o estabelecimento de relações entre os elementos unitários; a categorização; o captar o emergente em que a nova compreensão é comunicada e validada (MORAES; GALIAZZI, 2011, p. 12).

Na presente pesquisa delimitou-se como corpus da análise as informações contidas nos textos com as transcrições das entrevistas, conforme já mencionado. Os discursos presentes foram confrontados com as principais referências teóricas definidas pela pesquisa, considerando também os objetivos propostos. O processo de análise permitiu o agrupamento dos núcleos de sentido em quatro (4) categorias mistas.

As etapas tiveram como metodologia de observação a leitura e reflexão a respeito das respostas e análise dos seus conteúdos no que respeita aos temas e eixos principais que envolvem a EPT, currículo integrado, formação de professores, currículos obrigatórios, experiência docente, entre outros.

\section{RESULTADOS E DISCUSSÕES}

Após o mapeamento dos egressos no período determinado, foi registrado um total de 123 egressos nos três cursos analisados, em que o estudo, a partir disso, restringiu-se àqueles que ao responder um questionário declararam terem seguido atuação na docência após a formação, o que corresponde a $21,8 \%$ do total, conforme mencionado anteriormente.

Após contato prévio com os egressos que estavam atuando na docência, (12) pertencentes aos três diferentes cursos pesquisados se disponibilizaram a participar das entrevistas, constituindo suas respostas o corpus de análise.

O processo de análise das entrevistas permitiu o agrupamento dos núcleos de sentido em 04 categorias mistas (pois resultam do diálogo entre objetivos, referencial teórico e/ou emergiram das narrativas durante as entrevistas).

As categorias compreenderam: 1) Contribuições para a formação de professores; 2) Fragilidades na formação segundo os egressos; 3) Redimensionamentos na Formação em Licenciatura no Instituto Federal e 4) Precariedade na discussão sobre Currículo Integrado e EBPT. Dentro de cada uma das três primeiras categorias principais foram elencadas subcategorias para uma melhor compreensão e facilitar a análise dos resultados. Cabe destacar que a categoria 4 se faz presente neste conjunto, pois percebeu-se que as dimensões do currículo integrado e EBPT constitui-se um elemento frágil no currículo de formação de professores analisado nesta pesquisa.

Dentro de cada uma das 4 categorias foram elencadas subcategorias para uma melhor compreensão e facilitar análise dos resultados, as quais compreenderam:

Categoria 1 - Contribuições para a Formação de Professores, a qual foi subdividida em 1a) Importância do Pibid; 1b) Papel dos estágios na formação; 1c) Professores trabalham juntos, currículo integrado e interdisciplinaridade e 1d) Atividades de laboratório. 
Categoria 2 - Fragilidades na Formação Segundo os Egressos, subdividida em 2a) Pouca regência de classe; 2b) Carência de práticas de laboratório e 2c) Pouco conhecimento sobre currículo integrado.

Categoria 3 - Redimensionamentos na Formação em Licenciatura no Instituto Federal, que compreendeu as subcategorias 3a) Disciplina de Libras desde o Início, 3b) Fragilidades em Educação Especial e 3c) Antecipação e mais Tempo para Estágios Curriculares.

\section{Categoria 4 - Precariedade na discussão sobre Currículo Integrado.}

As categorias e subcategorias apresentadas anteriormente estão descritas seguir, procurando apontar os principais elementos indicados pelos(as) entrevistados(as), referencial teórico e análises.

\section{Categoria 1 - Contribuições para a Formação de Professores}

Nessa categoria foram analisadas as contribuições da formação para a docência ofertada pela instituição. Cabe destacar que são inúmeros os desafios na formação de um professor, principalmente os que futuramente se dedicarão à Educação Básica.

O êxito no processo de ensino-aprendizagem passa pela experiência do professor em sala de aula. Como, entretanto, essa experiência em sala é resultado de tempo na docência, torna-se imprescindível a execução de estágios devidamente acompanhados e avaliados pelos docentes do curso de formação, e que a instituição tenha clareza dos objetivos e da proposta do educador que visa a formar, conforme propõem Pimenta e Lima (2017a).

Nesta primeira categoria serão analisados pontos relacionados às contribuições que as graduações proporcionam para a formação, destacando o papel dos estágios e sua importância, bem como o do Programa de Bolsas de Iniciação à Docência (Pibid), dos laboratórios e das disciplinas curriculares, e por fim o trabalho conjunto com professores, currículo integrado e a interdisciplinaridade.

\section{1a) Importância do Pibid}

No intuito de complementar a formação e preparar o futuro docente para exercer sua profissão após a formação, o Ministério da Educação, por meio da Coordenação de Aperfeiçoamento de Pessoal de Nível Superior (Capes), dentro do escopo da Política Nacional de Formação de Professores, criou o Estágio de Docência e o Programa Institucional de Bolsas de Iniciação à Docência (Pibid) por meio da base legal Lei no 9.394/1996, a Lei no 12.796/2013 e o Decreto no 7.219/2010.

O Pibid tem como objetivo incentivar a carreira docente, com ênfase em algumas disciplinas, mas de forma geral autorizando projetos em todas as áreas do ensino. Interdisciplinaridade, criação, experiências, superação de problemas também são outros dos tantos aspectos trabalhados neste projeto.

Esse estímulo ao discente, desde a primeira parte do curso de Licenciatura, eleva a qualidade da formação e promove a observação e a reflexão sobre a prática profissional no cotidiano das escolas públicas de Educação Básica. O reflexo positivo e a importância do Programa são apresentados por diversos dos entrevistados. Notou-se uma fa- 
cilidade maior para o exercício da docência, no período pós-formação, para aqueles que participaram do Programa, a exemplo de um egresso que afirmou "a minha participação no Pibid já me inseriu no contexto da escola" (Egresso 6), o que é um dos elementos de destaque que permeia uma diversidade de falas a respeito da atividade em sala de aula, antes mesmo dos próprios estágios. A proposta do Pibid de conectar os licenciandos ao ambiente escolar atende muito bem à proposição de ampliar o contato das instituições de ensino superior à comunidade e ao trabalho de educador.

Percebe-se que o Pibid tem um papel fundamental no processo de formação dos licenciados pelo IFFar, conforme Ramos (2017) ao analisar a temática "O Pibid de Química e Biologia do IFFar: entre-lugar de auto(trans)formação permanente com professores" apresentada ao Programa de Pós-Graduação em Educação pela Universidade Federal de Santa Maria e demonstra o potencial do Programa e "suas dinâmicas e desdobramentos de auto(trans)formação permanente com os professores e alunos bolsistas" (2017, p. 31).

\section{1b) Papel dos estágios}

Os estágios são um dos pontos que compõe esta categoria e apesar de serem de suma importância para a formação dos educadores entrevistados, ficou evidente a necessidade por parte destes de ampliação da oferta dos estágios regulares nos currículos, demonstrando como a questão transcorre por todo este trabalho e dialoga com as categorias estabelecidas.

Segundo Pimenta e Lima (2017a), os estágios são promotores de diversas discussões sobre os objetivos da instituição formadora e da escola na qual o licenciando irá atuar, e que passam muitas vezes o pouco entendimento tanto da parte teórica quanto das atividades práticas a serem realizadas, ultrapassando a questão geralmente acordada que remete aos estágios como "parte prática" da formação do(a) educador/a. A superação desta dicotomia decorre pelo entendimento e superação entre os conceitos (p. 27), promovendo a práxis como uma alternativa viável a este processo.

A valorização da importância e necessidade dos estágios foi apontada por diversos entrevistados. E11 afirmou que a sua formação havia sido muito boa, com PPC completo, ressaltando as disciplinas da área específica, mas também as que se referem à parte didática e pedagógica, na construção dos materiais didáticos e realização dos estágios ("disciplinas pedagógicas voltadas ao real condicionamento das escolas públicas, trazendo propostas reais e possíveis de metodologias de ensino, as disciplinas pedagógicas que expuseram algumas práticas de ensino; e a prática em si através dos estágios") e isso indica que há uma boa base de formação curricular apresentada aos estudantes, contudo ainda há pontos que precisam de mais atenção. O(s) estágio(s) é(são) um deles, tanto nas pesquisas que têm sido realizadas nos próprios cursos de Graduação a respeito do tema quando por autores mais clássicos, como Pimenta e Lima (2017a) indicadas anteriormente.

Não foram apontados, contudo, apenas pontos positivos em relação à formação e aos estágios realizados. Quando questionado sobre quais aspectos foram relevantes para sua atuação profissional, um egresso destacou o processo como um todo até o momento, mencionando: 
Para mim o que mais foi importante durante esses quatro anos, foi a parte dos estágios, porque na verdade o conteúdo, se tu não sabe, se tu não consegue aprender, no momento que precisas, tu corre atrás, agora a organização de uma aula, o planejamento, o desenvolvimento... Isso foi muito importante durante os quatro estágios que tivemos, com professores que souberam muito bem nos conduzir (Entrevistado 4).

Este sentimento de falta, destacado pelo Entrevistado 4, está presente em diversas outras falas de egressos participantes desta pesquisa, apontando que existe uma ligação estreita entre a importância dos estágios por um lado e por outro as dificuldades no decorrer do processo. E7 destaca que "o que eu manteria também é a questão dos estágios, com certeza, isso aí é importante, é das oportunidades de entrar pra sala de aula desde o princípio do curso, seria isso que eu manteria", evidenciando o papel dos estágios no processo de formação.

O exercício de inserção na realidade escolar, quando permeado de análises do processo (OLIVEIRA, NASCIMENTO, 2019, p. 3.983) é fundamental, tal como destaca a entrevista 9: "estágios desde os anos iniciais fizeram com que nos preparassem para enfrentar os desafios", promovendo o espaço de aprendizado juntamente com as dificuldades e aprendizados da realidade de sala de aula. Destacando por fim todo este contexto de práxis diante dos desafios da docência, afirma-se na entrevista 9: "Acredito que tenha superado muito bem eles" (E9), e ressalta a importância de discutir os estágios como principal pressuposto na formação docente em instituições de ensino superior que preparam para a docência.

Percebe-se, contudo, que não foi apresentada por nenhum egresso alguma discussão a respeito do modelo de estágio que lhes era apresentado, fazendo com que seja importante destacar que em geral as disciplinas de estágio remetem muito mais à própria atividade docente do licenciando nas escolas em que deve cumprir as atividades, com alguma parte teórica, promovendo o que já denominamos como uma dicotomia persistente.

\section{1c) Atividades de laboratório}

Considerando o papel dos estágios, disciplinas específicas e pedagógicas e laboratórios como um conjunto mais amplo, é perceptível que os currículos dos cursos de Licenciatura são bastante promissores. E5 destacou que os "laboratórios, práticas de laboratório e modelos didáticos" são aprendizados "que utilizo até hoje na minha atuação profissional", destacando-os como aspectos fundamentais na sua formação.

Da mesma maneira que E7, afirmou que atividades em laboratório, juntamente com as metodologias diferenciadas que experienciou ao longo do curso, o compromisso com "a qualidade, solucionar situações-problema, influenciar na formação de um cidadão crítico, reflexivo [...] a questão da ética profissional" são destaques em sua carreira. Podemos considerar então que este é um dos eixos principais da formação dos educadores no IFFar campus Alegrete. 
Quando questionado sobre o que manteria no curso, considerando tratar-se de dimensões importantes para sua atuação profissional E5 mencionou que "manteria as práticas em laboratório, com certeza", cabendo ressaltar que o egresso pertence ao curso de Licenciatura em Ciências Biológicas, no qual as atividades de laboratório precisam fazer parte da rotina formativa.

E7 destacou a utilização dos laboratórios tanto na prática pedagógica em si quanto no incentivo à pesquisa para os licenciandos, como é possível verificar no trecho a seguir. E7 afirma que o que manteria "seriam as práticas laboratoriais que são muito interessantes porque é uma forma da gente levar um conhecimento diferenciado para nossos alunos, no dia a dia deles. É essencial que tenham as práticas laboratoriais" (E7, egresso do curso de Licenciatura em Química).

Para Krasilchik, $(2008$, p. 86) ao falar das aulas práticas em Biologia destaca que:

As aulas de laboratório têm um lugar insubstituível nos cursos de Biologia, pois desempenham funções únicas: permitem que os alunos tenham contato direto com os fenômenos, manipulando os materiais e equipamentos e observando organismos. $\mathrm{Na}$ análise do processo biológico, verificam concretamente o significado da variabilidade individual e a consequente necessidade de se trabalhar sempre com grupos de indivíduos para obter resultados válidos. Além disso, somente nas aulas práticas os alunos enfrentam os resultados não previstos, cuja interpretação desafia sua imaginação e raciocínio.

O texto citado corrobora a fala (narrativa) dos licenciados quando mencionam a necessidade de atividades em laboratório, destacadas em diversas entrevistas. Ainda conforme Krasilchik (2008), essa prática infelizmente não acontece, pois além da atividade/prática de laboratório ser reduzida, ao invés de dar oportunidade para os alunos se defrontarem com os fenômenos biológicos sem expectativas predeterminadas, as oportunidades muitas vezes são perdidas, pois elas são organizadas seguindo um roteiro predeterminado visando a encontrar respostas certas e não para resolver problemas, fazendo com que a atividade de laboratório se reduza a confirmar uma teoria.

\section{1d) Professores trabalham juntos, currículo integrado/interdisciplinaridade}

Outro aspecto apresentado como positivo foi a fundamentação para as disciplinas básicas do currículo. Como exemplo o E6 cita as disciplinas de fundamentos da Matemática: "No meu caso assim, da Matemática, eu acho muito interessante, sei que é muito importante ter as disciplinas do conteúdo específico, os conteúdos de Matemática, mas também interessante ter as que nós chamamos, as didáticas".

O E10 também apontou as disciplinas específicas como compositoras deste contexto de formação que foram importantes na sua graduação: "Outro aspecto foram as poucas aulas práticas, que também influenciam bastante depois na nossa atuação, que nós já temos uma noção de como realizar uma aula prática.

O terceiro aspecto, então, é a construção de modelos didáticos: "nós tivemos umas quantas disciplinas, que a gente construía material pedagógico, para auxiliar então na explicação, na interpretação dos alunos do conteúdo", compartilhado por E3, que afirma ser o "enlace entre teoria e prática" algo que destacaria, bem como as práti- 
cas profissionais integradas (PECs) já citadas anteriormente. Partindo destes elementos e da concepção de uma educação integradora, percebeu-se a importância das práticas pedagógicas relacionadas aos currículos integrados.

As narrativas permitem sugerir que as atividades integradas são fundamentais na busca por uma reformulação da formação de professores segundo a EPT.

\section{Categoria 2 - Fragilidades na formação segundo os egressos}

Diante do que foi apresentado anteriormente, nos pontos que foram indicados como fundamentais para o processo de formação, os egressos também foram questionados a respeito daquilo que consideravam como as fragilidades ou o que mudariam em seus respectivos cursos. Este questionamento tem como objetivo verificar quais os elementos que foram menos eficientes na formação. As narrativas são apresentadas nas subcategorias: "Pouca regência de classe"; "Carência de práticas de laboratório" e "Pouco conhecimento sobre currículo integrado".

\section{2a) Pouca regência de classe}

Os estágios foram fundamentais e destacados no processo de formação dos educadores que participaram da Parte 2 desta pesquisa, sendo apontado por eles como um ponto a ser mantido e valorizado dentro das licenciaturas do IFFar campus Alegrete.

Também são considerados, contudo, pontos frágeis e que necessitam atenção, posto que para os entrevistados, há necessidade de mais tempo de estágio de regência de classe e mais disponibilidade de estágios ao longo da Graduação, e que isso ocorra desde seu início e não apenas na metade final, como é ofertado atualmente. Gatti (2017), ao tratar da formação de professores, aponta que há necessidade de se reformular suas estruturas curriculares e algumas concepções a respeito da educação muito arraigadas ao modelo educacional ainda do século 20 . A autora afirma que:

Dúvidas surgem sobre como formar esses docentes, quais são as bases institucionais e curriculares mais condizentes com os desafios que as novas gerações estão a colocar, que os novos conhecimentos colocam, que novas e conflitantes relações no social se mostram desafiando nossas compreensões (GATTI, 2017, p. 723).

Estes conflitos e transformações refletem-se no ambiente escolar e fazem parte das dificuldades pelas quais passam os estudantes de Licenciaturas na compreensão dos contextos de atuação e apoio teórico. E1 aponta que gostaria de um “Menor tempo de estágio de observação e maior tempo de estágio de regência, estágios desde o início do curso e não somente no final, tempo maior de estágio de regência", ao ser questionado sobre esta questão, demonstrando de forma contundente um ponto reiterado por diversos(as) entrevistados(as).

A experiência do estágio é um momento particular a todo licenciando e pode ter diversos resultados individuais, mas pensando de forma coletiva, percebe-se que os currículos dos cursos em geral seguem uma estrutura fragmentada, o que pode colaborar para que estágios e disciplinas teóricas da educação tornem-se frágeis. Tais aspectos também são apontados por Gatti (2017, p. 731) quando apresenta um panorama da formação de educadores no Brasil. Ela identifica que "as licenciaturas caracterizam-se 
por uma formação fragmentada, intra e intercursos, com currículo fragilizado e estágios curriculares com problemas em sua realização efetiva", o que a autora define como aspectos que não contribuem para o processo de profissionalização docente "e nem para a construção de uma identidade profissional e sua valorização" (2017, p. 731).

Assim, o entrevistado E7 afirma que seria necessário entrar em sala de aula já no primeiro semestre do curso de Licenciatura: "Eu acho que o que eu modificaria no curso, eu acho que desde lá do primeiro semestre, eu acho que teria que ter um incentivo bem maior, pra nós como licenciandos entrar pra uma sala de aula, de promover ainda mais a pesquisa"; já E4 observa que há "dificuldades envolvendo o longo tempo entre formação e o início da atuação docente". Ou seja, os(as) entrevistados/as apontam em diversos momentos que o contato com o ambiente escolar (ou a falta dele) é um dos aspectos que dificultaram o processo de formação ou mesmo de confiança dentro da sala de aula quando de suas regências.

Neste sentido o E8 afirma que foi um processo difícil a transição de aluno em formação para docente, e que o ambiente em sala de aula lhe exigia artifícios que não havia aprendido até então, e por isso a importância de mais ambientação com as escolas, alunos e aula ("O que eu mudaria no curso, eu acho que é a mesma coisa que te disse anteriormente em relação à experiência em sala de aula, eu acho que faltou bastante isso. O estágio começa quando a gente está no terceiro ano, então eu acho que a gente passa 2 anos sem ter contato com a sala de aula, então quando chega no terceiro ano, vai para o estágio e tem muita gente que não gosta. Eu me adaptei, mas assim, tem gente no geral que vai para o estágio e vê que não é aquilo que queria, a gente passa esses 2 primeiros anos sem ter contato com a sala de aula, com o aluno, não sabe como é que é, não sabe como lidar").

Ainda neste sentido, há a fala de E1, que afirma "Eu acho que seria necessário, assim, mais a regência, ter mais tempo em sala de aula, o curso em si teria que ser mais prático mesmo, bastante prática, bastante regência, para realmente a pessoa chegar ao final e ter aquela certeza: Não, eu realmente quero ser docente! Porque tu [.] entrou em sala de aula, teve a oportunidade, várias oportunidades, de estar em sala de aula e verificar, vivenciar, porque a vivência é bem diferente da teoria, da faculdade, do mundo acadêmico, é bem diferente. A vivência é algo assim [.] bastante desafio". Este relato é extremamente contundente e demonstra que se deve refletir continuamente sobre esta temática na formação docente.

O Pibid como instrumento de inserção dos licenciandos no cotidiano de escolas da rede pública de educação é positivo, entretanto os programas de estágios devem atingir a todos os discentes e de modo uniforme. É muito importante que os docentes do IFFar avaliem, debatam e construam a aprendizagem juntamente com os alunos, proporcionando a eles o maior número de experiências possíveis de regência, pois na maioria dos casos é apenas no estágio que serão feitos os primeiros contatos com a realidade escolar. Este mesmo quadro ocorreu na pesquisa apresentada por Oliveira e Nascimento (2019), ao afirmarem que nas suas análises sobre o Instituto Federal de Educação, Ciência e Tecnologia do Maranhão (IFMA), "observa-se que a maior parte dos acadêmicos nunca tiveram uma experiência docente antes da disciplina de estágio supervisionado, perfazendo $62 \%$ dos questionados, o que reforça sua importância para os acadêmicos 
dos cursos de licenciatura" (OLIVEIRA, NASCIMENTO, 2019, p. 3.987). Estas similitudes podem indicar que a discussão sobre os estágios e as demandas dos licenciandos são tema para reflexão nos Institutos Federais como um todo, e podem se referir ao modelo ainda em construção destas instituições como formadoras de professores.

\section{2b) Carência de práticas de laboratório}

Verifica-se a relevância das práticas laboratoriais no processo de formação dos professores dos cursos de Licenciatura, que já foi mencionado anteriormente como um aspecto fundamental na formação (Categoria 1 - Contribuições para a formação) e retorna aqui como apontamento de fragilidade em relação a este mesmo processo no contexto analisado.

A utilização dessa ferramenta tão importante no processo da aprendizagem deve ser um constante esforço, pois, além de gerar nos alunos um entendimento mais abrangente dos conteúdos, contribui na superação da dicotomia teoria x prática e auxilia na superação do modelo de ensino no qual o aluno é um mero espectador e não participa do processo de construção do seu conhecimento. Conforme narrativas, foi possível constatar sua importância para o correto uso dessa ferramenta no dia a dia do ensino, mas também algumas carências e oportunidades de melhorias desse instrumento.

De um modo geral, o termo laboratório foi mencionado sempre atrelado a fragilidades do curso, ou também como um dos pontos com necessidade de melhorias. Praticamente todos entrevistados têm a consciência da importância das aulas práticas no processo de aprendizagem. O egresso (E1) declarou que, "o laboratório é a associação da teoria com a prática", mas que durante o curso "foi pouco tempo de atividades práticas". Na sua maioria, os entrevistados declararam a necessidade de se ter um "maior tempo de laboratório" como um dos aspectos mais relevantes na formação.

Uma das principais fragilidades constatadas pelos discentes foi a falta de suporte cognitivo oferecido pelos cursos aos futuros professores na condução de práticas em laboratório. Muitos egressos declararam que "faltou domínio de laboratório" (E1) e mais subsídios teóricos e metodológicos de como conduzir as aulas práticas. E10 apontou que uma das fragilidades da sua formação era "a falta de aulas práticas, tínhamos poucas aulas práticas no decorrer da formação". Ou seja, os resultados das entrevistas apontam para este elemento, que é por um lado fundamental no processo formativo do educador (neste caso a Matemática, Química e Ciências Biológicas).

Diante da associação envolvendo fragilidades/aulas práticas, E1 relata:

Na minha formação, como licenciatura em química eu hoje olhando pra trás, vejo que as fragilidades do curso, em si, teve muita parte pedagógica, mas eu penso assim, como na parte de química as fragilidades, seria o domínio mais em laboratório, que até hoje eu não consigo me sentir totalmente preparada pra levar um aluno, a turma inteira no laboratório e saber que eu vou conseguir dominar a turma e saber ter os conhecimentos, eu acho que a parte de laboratório faltou (Entrevistado 1). 
A narrativa do licenciando expõe a insegurança e a fragilidade em relação a esse aspecto importante na formação do professor. Conforme Krasilchik (2008), embora a importância das aulas práticas seja amplamente reconhecida, conforme várias narrativas dos licenciados, elas ainda são pouco contempladas nos cursos de Biologia. Os professores alegam vários fatores para que elas não se efetivem (tempo insuficiente para planejar, dificuldades para controlar a turma, falta de equipamentos). A autora menciona que embora esses fatores possam ser limitantes, nenhum justifica a ausência e desorganização de aulas práticas.

Um pequeno número de atividades interessantes e desafiadoras para o aluno já será suficiente para suprir as necessidades básicas desse componente essencial à formação dos jovens, que lhes permite relacionar os fatos às soluções de problemas, dando-lhes oportunidades de identificar questões para a investigação. Elaborar hipóteses e planejar experimentos para testá-las, organizar e interpretar dados e, a partir deles, fazer generalizações e inferências (KRASILCHIK, 2008, p. 87).

Nesse contexto, a autora ressalta que tão prejudicial quanto a ausência das aulas práticas é o fato destas, quando acontecem, serem realizadas de forma desorganizada, em que os estudantes, sem orientação, não sabem como proceder, ficando com uma visão distorcida do significado da experimentação no trabalho científico.

\section{2c) Pouco conhecimento sobre currículo integrado}

Como foi mencionado na categoria referente ao currículo integrado e sua importância para a formação, é imprescindível sua valorização no sentido de promover uma educação integral. Aires (2011) destaca que o currículo integrado tem quatro dimensões principais: a integração das experiências; a integração social; a integração do conhecimento e a integração como uma concepção curricular. ${ }^{3}$

Os egressos dos cursos de licenciatura do IFFar Campus Alegrete apontaram pouco conhecimento a respeito da temática. E5, por exemplo, afirma que "Eu li e a gente trabalhava sobre currículo integrado no curso normal e depois lá no IFF em Biologia a gente viu alguma coisa também, não muito. Mas na escola a gente trabalha com currículo integrado, por exemplo em projetos, então todas as áreas participam daquele projeto. Matemática, Ciências, Geografia. Todas as áreas". Esta fala ressalta uma questão primordial quando se trata de currículo integrado: a confusão regular que ocorre entre este conceito e a interdisciplinaridade.

Quando os egressos foram questionados se haviam lido ou trabalhado com algo relacionado ao currículo integrado, E6 comentou: "Olha, currículo integrado não me recordo nada assim específico, durante a Graduação, poderia ter sido sim comentado pelas professoras, mas não foi alguma coisa que me marcou, que me chamou muita atenção porque eu não tenho em mente sobre currículo integrado". E diante do questionamento sobre o contato com a Educação Profissional e Tecnológica durante a for-

Utiliza-se das concepções de James Beane (1997); para mais informações ver em AIRES (2011). 
mação E8 disse que não teve "essa experiência, assim, mesmo sendo num lugar que é de educação profissional e tecnológica. Não, a gente não teve essa experiência, só teve experiência com Ensino Fundamental e com a EJA".

Estas falas apontam um horizonte de discussão. Por um lado, a necessidade de trabalhar os conceitos e popularizá-los. Para Aires (2011), há que se atentar para estas confusões conceituais. Segundo a autora, é possível considerar que há divergências entre os conceitos em si, em razão do aprimoramento das pesquisas sobre eles. Dito isto, Aires afirma que:

No entanto, a principal razão para que estes dois termos não possam ser considerados sinônimos, no nosso entendimento, diz respeito aos campos de estudo a que estão relacionados. Ou seja, a interdisciplinaridade parece estar mais relacionada com a epistemologia das disciplinas científicas, com o ensino superior e a pesquisa, enquanto que a integração curricular parece estar mais relacionada com a epistemologia das disciplinas escolares, com o ensino médio e fundamental (AIRES, 2011, p. 225).

A integração curricular tem seus pressupostos intimamente ligados ao trabalho com as problemáticas do cotidiano dos alunos. A autora afirma que esta seria uma das principais diferenças para com a interdisciplinaridade, "a explicação para esse argumento consiste no fato de que a interdisciplinaridade pressupõe a organização curricular por disciplinas [.] Já a integração curricular não parte das disciplinas, mas dos centros de interesse" (AIRES, 2011, p. 227), apenas após isso são elencados os conhecimentos necessários (disciplinas). Por fim, vale destacar que:

Portanto, consideramos que a principal diferença entre os dois termos consiste no fato de que a interdisciplinaridade (seja na concepção hegemônica ou crítica) está relacionada ao aspecto interno da disciplina, ou seja, ao conteúdo. Enquanto que a integração curricular está relacionada ao aspecto externo à disciplina, ou seja, à problemática (AIRES, 2011 p. 227).

Desta forma, outro âmbito da discussão é verificar os motivos pelos quais estes egressos não conseguiram apontar os aspectos básicos que constituem a integração curricular e os caminhos que a instituição precisa seguir para que se consiga melhorar estes índices e promover, como menciona Gatti (2017), um objetivo conjunto da instituição diante da sua proposta de formação.

A formação de educadores que já exercem suas profissões preparados para os currículos integrados parece ser uma das metas a serem executadas, e como afirmam Araújo e Frigotto (2015), "procura-se, com isto, formar o indivíduo em suas múltiplas capacidades: de trabalhar, de viver coletivamente e agir autonomamente sobre a realidade, contribuindo para a construção de uma sociabilidade de fraternidade e de justiça social” (p. 68).

\section{Categoria 3 - Redimensionamentos na Formação em Licenciatura no Instituto Federal}

Considerando os processos apresentados até o momento, (a primeira categoria, nas contribuições da formação diante dos currículos das licenciaturas e pontos que são fundamentais para os egressos, e posteriormente a segunda categoria, que se refere aos aspectos que foram considerados frágeis ou insuficientes) temos um denominador 
comum, os redimensionamentos considerados fundamentais para atender à demanda dos egressos dos cursos de licenciatura do IFFar Campus Alegrete para o futuro da formação.

Estes devem ser considerados um passo para o entendimento das expectativas e necessidades de estudantes de cursos de Licenciatura, principalmente quando se fala em Institutos Federais, dado que a oferta de graduações com o foco para formação de professores não era o eixo inicial da proposta destas instituições. Para compreender estes elementos foram formuladas as subcategorias que se referem à oferta da disciplina de Libras desde o início da Graduação, as fragilidades no que respeita à Educação Especial e, por fim, a questão dos estágios curriculares e sua antecipação.

Para isto será seguido o mesmo modelo apresentado até o momento, com o diálogo a partir das entrevistas juntamente com o aporte teórico, contando com Mendes (2017) para pensar a Educação Especial nos Institutos Federais no Brasil, e Oliveira e Nascimento (2019) pensando o processo do estágio.

\section{3a) Oferta de Libras desde o início da formação}

A Lei no 10.436/2002 reconheceu a Língua Brasileira de Sinais (Libras) como meio legal de comunicação e expressão dos surdos e desde 2005 é obrigatória para os cursos de Licenciatura, Pedagogia e Fonoaudiologia.

Conforme os PPCs dos cursos de Licenciatura do Campus Alegrete, Libras compõe a matriz curricular de disciplinas de Formação Básica e é ofertada no 60 semestre nos cursos de Licenciatura em Química e Matemática e no 70 semestre no curso de Licenciatura em Ciências Biológicas, com uma carga horária de 36 horas. Esses cursos ainda trazem a disciplina de Libras II, de forma eletiva.

Conforme destacado nas entrevistas, as disciplinas de Libras e Educação Especial são alocadas muito tardiamente no currículo, talvez até não visadas devido ao contexto de muitas disciplinas obrigatórias. E6 argumenta que "Em vista desse desafio que eu estou passando, tanto as disciplinas de Libras quanto a disciplina de atendimento especializado, deveria ser no início e não só lá nos últimos semestres, desde o começo", juntamente com E2, cuja fala também destaca a necessidade de Libras na matriz curricular inicial.

Neste sentido, as falas são consonantes ao se referirem à acessibilidade e inclusão de alunos, e foram indicadas com algumas das principais fragilidades dos cursos de Licenciatura averiguados. Primeiro temos a indicação da disciplina de Libras, que foi apontada como fundamental desde o início do curso, de forma a estar disponível aos alunos ao longo de sua Graduação, o que tornaria mais atrativa aos acadêmicos e assim traria um novo aspecto na formação: a preparação para receber e ajudar na aprendizagem de alunos a partir do conhecimento de Libras.

\section{3b) Fragilidades em Educação Especial}

Devido ao apontamento iniciado na subcategoria anterior, temos em seguida a questão do contato com a temática da Educação Especial, a qual é apontada também como fundamental para o exercício pleno e de qualidade da docência dos egressos. A 
Educação Especial é tema de discussão há décadas no Brasil e tem sido estabelecida a inserção e inclusão de pessoas com algum diagnóstico cognitivo ou de outra natureza em diversos espaços da sociedade.

Pela legislação há o esforço em efetivar as regulamentações necessárias ao pleno direito dos cidadãos em participar da sociedade. Diante desta questão elencamos as seguintes leis que se referem à educação e inclusão, que fazem parte inclusive do escopo de funcionamento do próprio Instituto Federal Farroupilha ${ }^{4}$ no que diz respeito as suas ações inclusivas. A seguir estão elencadas as principais leis que se referem a este tema:

a) Lei de Diretrizes e Bases da Educação Nacional (BRASIL, 1996);

b) Política Nacional para integração da pessoa portadora de deficiência - Decreto no 3.298 (BRASIL, 1999);

c) Diretrizes Nacionais para a Educação Especial na Educação Básica (BRASIL, 2001);

d) Política Nacional de Educação Especial na Perspectiva da Educação Inclusiva (BRASIL, 2008); 39

e) Decreto 7.611 que dispõe sobre a Educação Especial, o atendimento educacional especializado e dá outras providências (BRASIL, 2011b);

f) Lei Brasileira de Inclusão da Pessoa com Deficiência - Estatuto da Pessoa com Deficiência (BRASIL, 2016). (MENDES, 2017, p. 38-39). ${ }^{5}$

As leis por vezes acabam não sendo acompanhadas de outras iniciativas mais efetivas nos contextos sociais em que precisam estar presentes, como é o caso da disponibilidade de disciplinas ou discussões sobre Educação Especial nos cursos de Licenciatura do IFFar. A fala exposta na entrevista 4 aponta diversos elementos que podem ser considerados fundamentais nesta discussão e da necessidade de ampliá-la, demonstrando um olhar humanizado e inclusivo para com seus educandos, conforme é possível verificar no trecho a seguir:

Eu senti muito a falta de uma disciplina voltada para atendimento individualizado, quando tem um aluno que tem algum diagnóstico, porque da nossa, ela era eletiva, e infelizmente não deu tempo da gente conhecer, são muitas né? Mas uma carga horária pequena, uma vez por semana, que estudássemos outros diagnósticos que uma criança pode ter, sempre voltada ao ensino de matemática e não de uma forma geral, por que nós sabemos que existe a Síndrome de Down, o Autismo, nós também seremos profissionais, é importante a gente saber, óbvio né? Mas não perder muito tempo sobre a lei né? O primeiro aluno autista eu sinto falta assim, de como eu vou ensinar matemática pra ele? Claro que cada caso é um caso, mas o que eu poderia fazer, do nível mais básico, do nível mais aprofundado. Sabemos que na matemática sempre que possível, tentamos usar material concreto, material manipulável, sim, mas como se dá a mente de uma criança, como podemos trabalhar a matemática nesse quesito (Entrevistado 4).

A fala do Entrevistado 4 demonstra a complexidade da realidade na educação, e conforme também o que já foi apontado anteriormente, coloca o licenciando/graduado diante de uma realidade por vezes muito diferente da discutida em ambiente acadêmico. Esta mesma entrevista aponta ainda qual rumo poderia ser conduzido quando se trata da efetivação desses conceitos ao longo da formação.

4 Ver mais em https://www.iffarroupilha.edu.br/a\%C3\%A7\%C3\%B5es-inclusivas

5 Educação Inclusiva IFs do Rio Grande do Sul e Santa Catarina. 
Mendes (2017), ao pesquisar a Educação Especial nos Institutos Federais brasileiros, afirma que:

Educação Especial é uma área de conhecimento da educação e uma modalidade da educação brasileira prevista na Lei de Diretrizes e Bases da Educação Nacional (LDB) - no 9.394/96, transversal a todos os níveis, etapas e outras modalidades da educação nacional. A ideia de modalidade implica exatamente metodologias diferenciadas, um modus operandi específico de desenvolver o trabalho educativo, no que diz respeito ao: currículo, tempo, avaliação, material, entre outras adaptações (p. 26). ${ }^{6}$

E este modus operandi significa justamente abrir espaço para uma qualificação maior dos professores em formação para que diante de uma realidade em sala de aula diversa e desafiadora das suas próprias práticas e concepções, este sinta-se preparado (ou amparado ao menos teoricamente) para exercer sua profissão, para que possa promover uma educação que leve em consideração a diversidade.

\section{3c) Antecipação e mais tempo para estágios curriculares e práticas de laboratório}

Em sua maioria, durante as entrevistas os egressos declararam ser "pouco o tempo de estágio de regência" e outra afirmou que "não estava preparada para ter um domínio sobre uma turma". Essa fragilidade é constatada, pois grande parte dos egressos afirmaram que tiveram frustrações nas primeiras experiências conduzindo uma turma em sala de aula. Segundo Pimenta e Lima (2017b), é fundamental que a instituição possua uma compreensão clara a respeito do seu foco no ensino e na formulação das disciplinas de estágio e didáticas, como apresenta no trecho a seguir:

Daí a necessidade de que, ao desenvolver o estágio, se tenha uma ideia clara a respeito da concepção de professor que se quer formar. No processo do estágio, a exigência do posicionamento faz-se fortemente presente, visto que é um momento do processo formativo no qual o futuro professor se depara com a realidade profissional docente (PIMENTA, LIMA, 2017b, p. 236).

Percebe-se, ao analisar o tema nas entrevistas e os apontamentos realizados até o momento, que os IFs ainda estão formulando suas bases no que respeita à disponibilidade dos cursos de Licenciatura na instituição. Assim, nem todos tiveram a oportunidade de participar do programa de incentivo à docência e que, apesar dos estágios de observação e de regência, o período de atuação em sala de aula foi insuficiente, sendo talvez importante dar atenção para as disciplinas da grade curricular para uniformizar as oportunidades a partir da carga horária obrigatória, ampliada com as participações em projetos, juntamente com as práticas de laboratório, que em conjunto com os estágios se apresentaram como uma questão que precisa outros direcionamentos futuros.

Em seu relato, E8 destaca sobre a experiência em sala de aula durante sua formação: "Durante os 4 anos do curso, o contato é somente nos 2 últimos anos e muitos somente aí chegam à conclusão que não querem seguir a profissão, mas talvez agora com as PECs, tenham inserido mais práticas e contato com a sala de aula". Já E9 afirma que seria interessante a disponibilidade de "estágios desde o início de cada semestre". Estes

Para verificar mais sobre Educação Especial e Educação Inclusiva no Brasil, ver mais em MENDES (2017) 
relatos ocorrem ao longo da pesquisa e demonstram uma necessidade para os egressos no decorrer de seu período de formação, de forma a apontarem isso em diversas entrevistas.

Pimenta e Lima (2017) observam que estágios têm diferentes concepções ao longo do tempo, e a adaptação da educação aos novos contextos socioculturais, como afirma no trecho a seguir:

Se no passado se tinha uma formação voltada somente para o domínio do conteúdo, hoje a discussão ganhou nova estrutura que soma-se ao currículo escolar, como a globalização da economia, produção de bens e serviços, diversidade cultural e reestruturação social, política e financeira mundial (PIMENTA; LIMA, 2017a, p. 25).

Tais necessidades exigem que as instituições formadoras de professores também busquem novas abordagens, tal como a elaboração de uma proposta de estágio que não se baseie apenas na dicotomia entre teoria e prática educativa, como regularmente acontece e que se mescla à situação apontada nas falas, em que é exposto o pouco tempo e pouca compreensão do próprio significado dos estágios no processo de formação.

\section{Categoria 4 - Precariedade na discussão sobre Currículo Integrado e EPT}

Com a metodologia de ensino dos cursos de Licenciaturas, considerando a estrutura curricular prevista em seus Projetos Pedagógicos (PPC), o IFFar Campus Alegrete garante ao discente uma formação geral, sólida e abrangente no conteúdo dos diversos campos da Biologia, Matemática e Química, o que foi confirmado pela pesquisa ao encontrar uma boa parte dos entrevistados que destacaram as disciplinas específicas como ponto forte para sua formação.

De acordo com os PPCs dos cursos, a adoção de uma metodologia coerente, proporcionando ao discente participar de atividades de ensino, deve ser utilizada desde o início do curso. Esse propósito é alcançado com a adoção de estratégias que visam, entre outros objetivos, a "proporcionar ao discente uma formação adequada com domínio dos conceitos fundamentais da área, com capacidade de compreender e ensinar os conteúdos".

Analisando, contudo, as entrevistas com os egressos que seguiram o exercício da docência após a formação, nota-se o pleno entendimento da importância das disciplinas voltadas para o ensino e a didática, mas seu distanciamento da atividade docente em si, como também já foi apontado pelos resultados até aqui. Ademais, verifica-se que a maioria dos egressos reconhece que a metodologia e a didática diferenciada da instituição proporcionam ao aluno a aprendizagem plena dos conhecimentos específicos e a aplicabilidade futura das experiências pedagógicas.

O Entrevistado 9 declarou que "no curso se aprende várias metodologias de como atender às necessidades dos nossos alunos", comprovando que o Instituto foi capaz, nesse caso, de fornecer ferramentas para o egresso na sua atividade de ensino. Assim, verifica-se que na formação acadêmica do futuro docente, tão importante quanto a aprendizagem dos conhecimentos necessários, é o modo como eles são transmitidos. A didática e o acompanhamento pedagógico exercidos durante o curso de Graduação servirão como base e referencial para o egresso na aplicação dos seus métodos de ensino. 
Em linhas gerais, as falas sinalizam para características de processos formativos convencionais, concebendo que as marcas de uma Educação Profissional e Tecnológica são frágeis e por isso a necessidade de avaliar os resultados verificando os pontos menos densos e propor rumos para a melhoria tanto da formação ampla quanto da efetivação de uma compreensão mais evidente e propositiva da EPT. Ou seja, o currículo integrado está deixando a desejar e não faz parte da memória do processo de formação destes educadores egressos da instituição, uma vez que somente falam sobre currículo integrado quando questionados e demonstram que estes conceitos não fazem parte da sua linguagem docente.

Flach e Forster (2015) apontam um elemento interessante para análise. Quanto à ampliação da formação de professores para além das universidades, passou a haver questionamentos sobre as diferenças entre estes espaços formadores, os autores destacam que a compreensão de formação ainda está muito atrelada ao modelo criado nessas instituições. É necessária uma concepção que seja readequada aos interesses e necessidades das novas instituições criadas e neste caso é possível utilizar esta reflexão para completar a análise sobre o rearranjo da compreensão de Educação Profissional e Tecnológica, reelaborando os fundamentos básicos para as Licenciaturas que atendam aos fundamentos desta proposta de ensino e formação de professores.

É clara a importância do papel do professor na formação do cidadão. O êxito no cumprimento desse dever social que desempenha é diretamente proporcional a sua capacidade profissional e, por conseguinte, na qualidade de sua formação.

O IFFar Campus Alegrete-RS, em seus cursos de Licenciaturas, tem como objetivo, de acordo com sua missão institucional, muito além de "treinar" docentes para repassarem mecanicamente aquilo que aprenderam, formar professores, transmitindo a base da reflexão na sua construção profissional, capazes de ponderarem o que deve ser ensinado e de que maneira podem contribuir para a igualdade na diversidade social, econômica, geográfica e cultural do nosso país. Para além de uma discussão geral, há que se considerar, como apontam Flach e Forster (2015), que os IFs também se reconfigurem para assegurar a criação de uma identidade que lhes seja particular, adequando-se aos elementos que compõem a sua realidade, não mais para preencher um espaço na formação de professores, mas sim para valorizar um conjunto de aspectos que se fortaleceu, porém ainda não se consolidou, que é uma educação voltada ao Ensino Profissional e Tecnológico dentro dos IFS e refletido na formação de profissionais advindos deste contexto.

Nesse cenário, o serviço docente, na perspectiva do exercício na modalidade da EPT, corrobora o intuito do IFFar de, por meio dos seus recursos pedagógicos, preparar docentes que possuam uma capacidade crítico-social, com pleno conhecimento teórico e habilitado para adotar um currículo integrado na sua docência. E, também como apontam Lustosa e Souza (2015), corroborando o que também ressalta Lima (2013), a formação docente para a educação profissional não deve estar apenas focada em tratar da técnica, e por isso uma compreensão omnilateral da educação é fundamental, para que aliando a teoria, a prática e a disponibilidade de uma formação reflexiva o educado oriundo do IF possa estar ciente de sua "concepção humana de sujeito" (LUSTOSA; SOUZA, 2015, p. 5) e reflexivo como professor. 
Analisando as entrevistas com os egressos, percebe-se um evidente desconhecimento teórico, tanto em questões que envolviam currículo integrado quanto aquelas relacionadas à Educação Profissional e Tecnológica. Essa incapacidade de grande parte dos egressos em identificar princípios básicos, experiências durante a formação e o emprego desses temas já na atividade docente, indica uma importante fragilidade da instituição.

Ao oportunizar um tempo para o entrevistado falar sobre currículo integrado, vários não souberam responder. O Egresso (E7) declarou que "Em princípio assim... eu não me lembro de ter contato com currículo integrado", outro que "lembro que os professores falaram sobre, mas não sei dizer o que é" (E6), demonstrando uma carência de conhecimento sobre o assunto.

Outra preocupação está relacionada a alguns equívocos em conceitos básicos, por exemplo, confundir currículo integrado com interdisciplinaridade. Ou também que a Educação Profissional e Tecnológica atende às demandas do mercado e garante a inserção do egresso no mercado de trabalho, elemento que Lima (2013) já havia mencionado, pelo fato de realmente tornar-se pertinente a preocupação com uma mecanização do ensino para EPT. Deve-se primeiro, contudo, ao menos é o que indica o resultado desta pesquisa, trabalhar os conceitos básicos que fundamentam esta modalidade de educação.

$\mathrm{Na}$ contramão da maioria, foi possível identificar dois egressos que afirmaram ter tido contato com o assunto. O primeiro é docente, atualmente, no IFFar, e "desenvolve o tema através de oficinas com os alunos". Já o segundo afirmou que seu conhecimento sobre o tema deve-se à realização, após formado, de um curso de especialização em gestão educacional.

O resultado da análise das entrevistas com os egressos contrasta, enfim, com a missão dos Institutos, que foram criados, por meio da Lei ํo 11.892/08, de 29 de dezembro de 2008, exatamente com o propósito de promover a educação profissional, científica e tecnológica com foco na formação integral do cidadão.

Conforme afirmam Chaves, Kaefer e Chuquel (2020), a partir da análise dos PPCs de cursos de Licenciaturas, concluem que embora nos PPCs dos cursos analisados tenha ficado explícita a perspectiva de promoção da integração curricular com vistas à profissionalização dos futuros professores para a Educação Profissional a partir do ensino ou do currículo integrado, na prática as ações ainda são tímidas. No mesmo sentido, Alves e Brancher (2020) mencionam que refletir sobre as trajetórias e vivências docentes na EPT promove o entendimento acerca das particularidades dessa modalidade educacional, principalmente quando se refere à qualificação do trabalho dos professores.

\section{CONSIDERAÇÕES FINAIS}

A pesquisa realizada teve como propósito analisar a contribuição dos cursos de Licenciatura na formação docente e sua inserção na docência, identificando as fragilidades ou atributos formativos entre egressos das turmas dos cursos de Licenciatura em Ciências Biológicas, Química e Matemática do IFFar Campus Alegrete entre os anos de 2010 e 2014. 
O estudo possibilitou uma percepção de como esses cursos vêm sendo ofertados pelos Institutos Federais de Educação, Ciência e Tecnologia, instituições estas relativamente novas na estrutura educacional brasileira e que se encontram em fase de expansão e consolidação, sendo movidas pela concretização de missões específicas, principalmente no que diz respeito à Educação Profissional e Tecnológica. Dessa forma, este trabalho se constitui uma ferramenta que poderá ser utilizada para adequação futura de práticas educativas e direcionamento de investimentos abrangendo os cursos de formação de professores pelos Institutos Federais.

No âmbito das entrevistas, os pontos positivos da formação docente no IFFar Campus Alegrete foram apontados os seguintes: os estágios curriculares como aspectos fundamentais, juntamente com o trabalho coletivo dos professores e na interdisciplinaridade, e por fim, o papel fundamental do Pibid em possibilitar a execução de atividades nas escolas do município, colocando os alunos licenciandos em ambiente de sala de aula, na compreensão do funcionamento do cotidiano escolar e podendo compartilhar experiências.

Os pontos considerados frágeis, apontados pelos(as) entrevistados(as), incluem a insuficiente regência em sala de aula, com muitas horas de observação e poucas de prática. A oferta de Libras também foi um elemento indicado como fragilidade, juntamente com a Educação Especial. Outro fato observado foi o distanciamento existente entre a matriz curricular dos cursos de Licenciatura do IFFar Campus Alegrete e a EPT, tendo como princípio que os Institutos Federais são instituições voltadas para a oferta dessa modalidade de ensino.

De acordo com os resultados do estudo e autores pesquisados, foi possível constatar que a atividade docente na EPT foi e está sendo marcada por uma enorme gama de profissionais de áreas distintas e sem a qualificação pedagógica necessária para a atuação nesta modalidade, o que faz com que seja necessário atentar para estes fatores, dado que o caráter de formação de professores nestas instituições ainda está sendo construído e necessita de redimensionamentos.

Este estudo oportuniza à instituição, por intermédio da identificação de fragilidades que emergiram das falas dos egressos, como o ajustamento de alguns processos de ensino e redimensionamentos formativos, no que respeita aos contornos das disciplinas de estágio curricular e quais são os seus objetivos e compreensão em relação aos elementos destacados (mais tempo para estágios, antecipação, teoria x prática), além de uma qualificação acadêmica que priorize a verdadeira missão, visão e valores do Instituto, que garanta uma formação de qualidade para os futuros professores, deve garantir de que ela esteja articulada ao propósito mais amplo dos Institutos Federais: a inclusão da Educação Profissional e Tecnológica como uma linguagem comum aos educadores formados nos cursos de Licenciaturas.

\section{REFERÊNCIAS}

AIRES, Joanez A. Integração curricular e interdisciplinaridade: sinônimos? Educação \& Realidade, Porto Alegre: Universidade Federal do Rio Grande do Sul, v. 36, n. 1, p. 215-230, jan./abr. 2011. Disponível em: http://www.redalyc.org/articulo.oa?id=317227056012 
ALVES, Ana Paula da C.; BRANCHER, Vantoir R. Um olhar sobre a docência do professor não licenciado na Educação Profissional e Tecnológica: uma pesquisa bibliográfica. Revista Contexto \& Educação, [S.I.], v. 35, n. 112, p. 82-101, 2020. Disponível em: https://www.revistas.unijui.edu.br/index.php/contextoeducacao/article/ view/10322. Acesso em: 15 ago. 2021.

ARAUJO, R. M. De L.; FRIGOTTO, G. Práticas pedagógicas e ensino integrado. Revista Educação em Questão, v. 52, n. 38, p. 61-80, 15 ago. 2015.

CHAVES, Taniamara.; KAEFER, Maria. Teresinha. V.; CHUQUEL, Daiane. R. Concepções e práticas relativas ao currículo integrado nas práticas como componentes curriculares em cursos de Licenciatura de um Instituto Federal de Educação. Revista Contexto \& Educação, [S.I.], v. 35, n. 112, p. 66-81, 2020. DOI: 10.21527/2179-1309.2020.112.6681. Disponível em: https://www.revistas.unijui.edu.br/index.php/contextoeducacao/article/view/10318. Acesso em: 15 ago. 2021.

FLACH, Ângela; FORSTER, Mari Margarete dos S. Formação de professores nos institutos federais: uma identidade por construir. In: REUNIÃO NACIONAL DA ANPED, 37., 2015. Florianópolis: Universidade Federal de Santa Catarina, 2015. p. 1-17. Disponível em: http://37reuniao.anped.org.br/wpcontent/ uploads/2015/02/Trabalho-GT08-4027.pdf

GATTI, Bernardete. Formação de professores, complexidade e trabalho docente. Revista Diálogos Educacionais, Curitiba, v. 17, n. 53, p. 721-737, 2017.

KRASILCHIK, Myriam. Prática de ensino de biologia. 4. ed. São Paulo: Editora da Universidade de São Paulo, 2008.

LIMA, Fernanda Bartoly. G. de. A formação de professores nos Institutos Federais - perfil da oferta. Revista EIXO, Brasília, v. 2, n. 1, p. 83-105, 2013.

LUSTOSA, Wigna Eriony A. de M.; SOUZA, Francisco das C. da S. As licenciaturas nos Institutos Federais - a formação de professores ofertadas por instituições de educação profissional. COLÓQUIO NACIONAL/EIXO TEMÁTICO III, 3., - Formação de professores para a educação profissional, 2015. Anais [...]. 2015 p. 1-9.

MENDES, Katiuscia Aparecida Moreira de Oliveira. Educação especial inclusiva nos Institutos Federais de Educação, Ciência e Tecnologia brasileiros. 2017. 167 f. Tese (Doutorado) - Universidade Federal de Goiás, Faculdade de Educação (FE), Programa de Pós-Graduação em Educação, Goiânia, 2017. Disponível em: https://repositorio.bc.ufg.br/tede/bitstream/tede/8139/5/Tese\%20-\%20Katiuscia\%20Aparecida\%20Moreira\%20de\%200liveira\%20Mendes\%20\%202017.pdf. Acesso em: 15 ago. 2021.

MORAES, R.; GALIAZZI, M. do C. Análise textual discursiva. 2. ed. rev. ljuí: Editora Unijuí, 2011. 224 p.

OLIVEIRA, Lueny A.; NASCIMENTO, Antonia G. do. A importância do estágio supervisionado na formação dos acadêmicos do curso de Licenciatura em Química do IFMA Campus Zé Doca. Brazilian Journal of Development, Curitiba, v. 5, n. 4, p. 3.981-3.994, 2019.

PIMENTA, Selma Garrido; LIMA, Maria Socorro Lucena. Estágio: diferentes concepções. In: PIMENTA, Selma Garrido; LIMA, Maria Socorro Lucena. Estágio e docência. Colaboração Érica Barroso Dauanny e Elisângela André da Silva Costa. 8. ed. São Paulo: Cortez, 2017a.

PIMENTA, Selma Garrido; LIMA, Maria Socorro Lucena. Estágios: avanços teóricos e práticos - um diálogo com diferentes autores. In: PIMENTA, Selma Garrido; LIMA, Maria Socorro Lucena. Estágio e docência. Colaboração Érica Barroso Dauanny e Elisângela André da Silva Costa. 8. ed. São Paulo: Cortez, 2017b.

RAMOS, Maria Rosângela S. O Pibid de química e biologia do IFFAR: entre-lugar de auto(trans) formação permanente com professores. 396 p. Tese (Doutorado em Educação) - Universidade Federal de Santa Maria, Santa Maria, 2017.

SILVA, Alany Alves da et al. O estágio supervisionado nos cursos de Licenciatura em matemática - contribuições e dificuldades. CONGRESSO NACIONAL DE EDUCAÇÃO., 6., Conedu 2019. p. 1-6. 